\title{
Data Gap Analysis for the Sectoral Planning of Dedopistskato Municipality on Landscape Basis
}

\author{
Nino Sulkhanishvili \\ Faculty of Exact and Natural Science, Ivane Javakhishvili Tbilisi State University, Tbilisi, Georgia
}

\section{Email address:}

Nino.sulkhanishvili@tsu.ge

\section{To cite this article:}

Nino Sulkhanishvili. Data Gap Analysis for the Sectoral Planning of Dedopistskato Municipality on Landscape Basis. Earth Sciences. Special Issue: Modern Problems of Geography and Anthropology. Vol. 4, No. 5-1, 2015, pp. 99-103. doi: 10.11648/j.earth.s.2015040501.28

\begin{abstract}
This electronic document is a "live" template. The various components of your paper [title, text, heads, etc.] are already defined on the style sheet, as illustrated by the portions given in this document. The abstract should be between 40 and 400 words.
\end{abstract}

Keywords: Sectoral Planning, Landscape Researches, Dedopistskato Municipality

\section{Introduction}

According to all 3 national communications on UNFCC (1997-1999; 2006-2009 and 2012-2014) Dedoplisttskaro municipality is most affected by climate change regions in Georgia [1,2]. As a result desertification and land degradation processes are widely observed in the region. The main strategy of fighting against desertification process and against the consequences of climate change shall be based on the protection and revival of different natural habitats and the species characterized to such habitats. In order to preserve such an environment, the degraded territories should be revived, the spheres of protecting natural resources in the region should be developed and their share in the economy should be significantly increased.

The aim of the given study is to create a precondition of the sectoral planning of Dedoplistskaro municipality on the landscape-environmental basis. The study gives a detailed description of the natural-resource potential based on the natural-territorial complexes, which gives us a possibility to plan the main economic directions within the mentioned municipality.

On the basis of the mentioned document an interactive map shall be drawn up, which shall be uploaded on a special web-site. The mentioned plan shall serve as a guide for the investors and other persons concerned in this project to define priorities of the directions to be taken and to plan proper activities on the mentioned territory.

\section{Study Area}

Dedoplistskaro municipality, the area comprising 2532 $\mathrm{km} 2$, occupies $22 \%$ of the territory of Kakheti region. It is situated between the Alazani and Iori River Gorges on the elevated hillock the lowest altitude of which $(90 \mathrm{~m}$ a.s.l) is located near the Mingechaur water reservoir, at the tributary of the Iori River. The Nikorastsikhe Mountain is situated on the highest elevation (1001 m a.s.l), located to the south of Dedoplistskaro town [3].

Dedoplistskaro region is rich with fertile lands and wide pastures, but it is poor with natural water resources and atmospheric precipitations. During summer months the air temperature reaches $35-400 \mathrm{C}$ here, which causes drought together with long dry periods. All of the mentioned cause the necessity of creating a high quality irrigation system for the agriculture - one of the leading field of economy on the background of ongoing climate changes and the necessity of working out and implementing those adaptation activities which are necessary for the region.

Dedoplistskaro municipality is in a strong deficit of water resources. The irrigation systems are completely disordered. Only $5 \%$ of the agricultural lands of the municipality is supplied with water. As a comparison, these data in Sagarejo municipality, which has almost same physical-geographic conditions, comprise $50 \%$ and mean value of whole Kakheti region comprises $40 \%$; as a result of intensive water-collection in the irrigation channels in Gardabani and Sagarejo, the mean annual flow of the Iori River is seven times reduced. 
To the south part of the region there is a Vashlovani Protected Areas. Its area comprises 10000 ha. There are some rivers on the territory which are becoming periodically dried. The territory is surrounded with mountains, their height doesn't exceed 520-580 $\mathrm{m}$ a.s.1, and the elevation of the central part ranges between $300-400 \mathrm{~m}$. To the south-west of the Vashlovani strict nature reserve, on the elevation of 90-150 $\mathrm{m}$ there is Eldari Lowland, which is the lowest part in the east Georgia. It is characterized with a flat surface, there are many badlands, dry gorges and uncultivated territories.

To the east of the municipality, the south and west parts of the territory are intensively used as winter pastures, which has a negative impact on the landscapes. The central and north parts of the municipality are mainly represented by agricultural lands, vineyards, gardens and other farm plots.

Agriculture is a leading sphere in the economy of Dedoplistskaro municipality. Despite the fact that the population of the municipality is $8 \%$ less than the population of Kakheti region, it plays an important role in the agricultural development of the region. For example, in 2001-2005 32\% of the total production of wheat, $13 \%$ of grape, $13 \%$ of beef was produced in this region. During the harvest the analogical index for the sunflower comprised 34\%. [4].

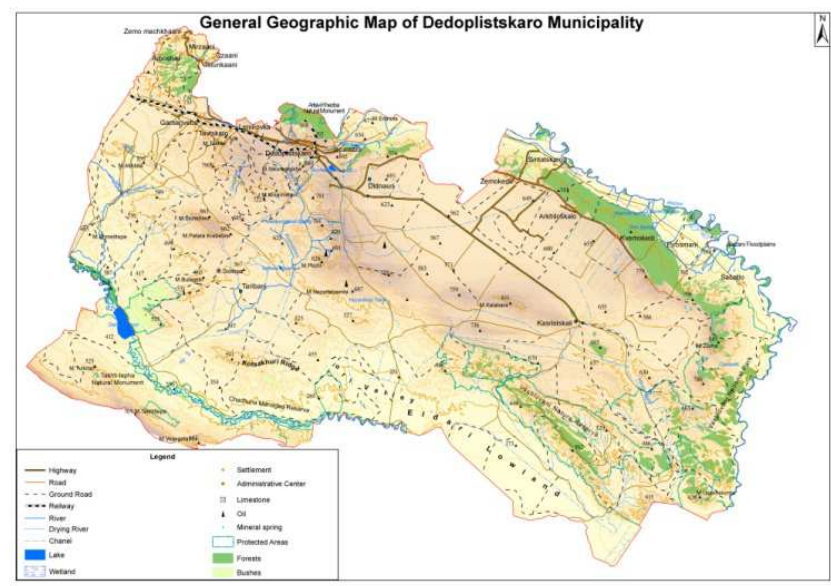

Figure 1. Dedoplistskaro Municipality

\section{Methodology}

Analysis and Synthesis of background information on Natural conditions and resources, socio-economic conditions, environmental issues, tourism, historical and cultural heritage, projects implemented on the territory of Dedoplistskaro municipality for the last 5 years by international support and the ongoing was implemented.

Consolidated information was verified by rapid assessment on above mentioned topics with participation of local government, local CSOs and general public.

Following thematic GIZ maps were developed under the study:

- Climate zoning map

- Agro-climatic map

- Hydrographic map

- Map of soils
- Map of degraded territories

- Map of protected territories

- Map of landscapes

- Map of population

- Map of natural resources

- Map of infrastructure

- Land cadastre map

- Map of pastures

- Map of tourism

- Map of historical heritage

- Map of rehabilitated wind-belts

Recommendations for decision-making processes on climate change adaptation within the each landscape were developed.

\section{Main Results}

\subsection{Agri-climatic Zonning}

Agri-climatic Zonning is important for the sectoral planning of the municipality

According to the selected zones it is possible to differentiate certain agronomic crops. For the reason of achieving the profitability of farming economy it is necessary to grow agronomic crops by taking into consideration their requirements towards the agro-climate factors and mainly considering their relation to the heating regime. The mentioned activity will serve as a contribution to the specialists of agriculture and to the farmers for producing this or that crops better and generally for the improvement of harvesting.

For selecting agro-climate zones from the climate parameters, an average air temperature per day and night more than $10^{\circ} \mathrm{C}$ and the totals of the atmospheric precipitations (in warm period, IV-X) are applied. Number of the indicated atmospheric precipitations (isohyet line) shows the mean precipitation value for the given zone. As a result 4 Agri-climatic Zones were identified.

The first agro-climatic zone is spread to the south, south-east and east parts of Dedoplistskaro municipality, on the altitude of $200-400 \mathrm{~m}$ a.s.l. The total of the active temperatures $\left(>10^{\circ}\right)$ is more than $4000^{\circ}$, the absolute maximum of the air temperature comprises $+39^{\circ} \mathrm{C}$, the absolute minimum comprises $-26^{\circ} \mathrm{C}$ (Eldari lowland). Annual number of atmospheric precipitations in the warm period of the year (IV-X) reaches 300-400 $\mathrm{mm}$.

This zone is characterized with dry sub-tropical climate. Here we can expect a wide distribution of cereals (wheat, corn and others), the ethyl-oil plants, sub-tropical persimmon. On some slopes, where the freezes do not exceed -14 and $-15^{\circ} \mathrm{C}$, there is a possibility of producing pomegranate, fig and olive fruit plants. Except this, peach, quince, apple, and pear trees, also vegetable and other fruit gardens may have a wide area of spreading.

The zone is less humid due to which, for ensuring normal vegetation of the mentioned crops the soil irrigation shall be needed (twice during the active vegetation period). Soil 
irrigation is sometimes desirable during other vegetation periods too.

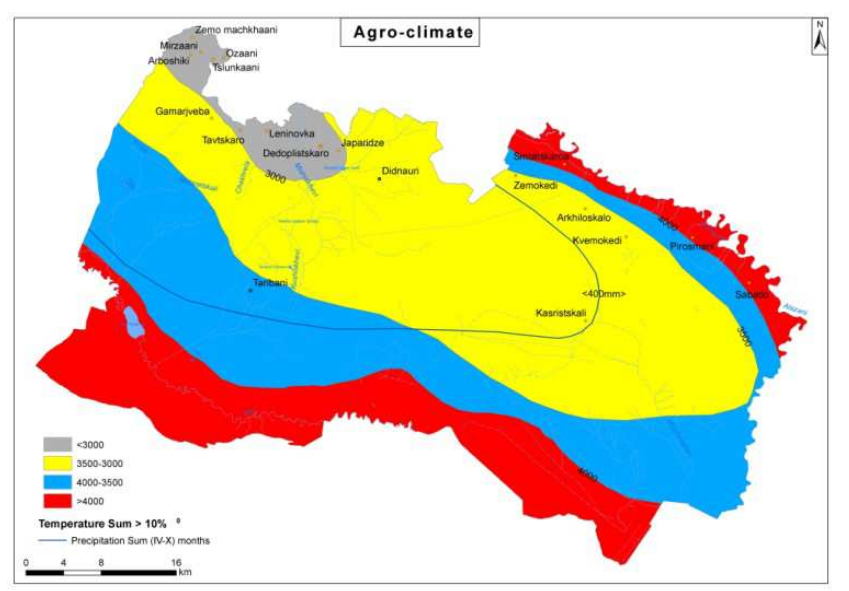

Figure 2. Agro-Climatic zones of Dedoplistskaro Municipality

The second agro-climatic zone borders with the first zone and it is spread to the elevation of 400-600 $\mathrm{m}$ a.s.l. The total of the active temperatures $\left(>10^{\circ}\right)$ is $3500^{\circ}$ and more than this, annual number of atmospheric precipitations in the warm period of the year (IV-X) reaches 300-450 mm.

This zone is characterized with warm climate. Here we can expect a wide distribution of corns and all species of vine (early, late). From the grapes grown in this region we can make high quality wines and material for producing high quality cognac. It is also possible to produce the technical ethyl-oily crops here - sunflower, sugar beet. In order to gain a guaranteed harvest from the mentioned crops it is necessary to provide soil irrigation (watering, reclamation - hoeing and getting rid of weeds).

In comparison with the first and second climatic zones, the third climatic zone is spread on relatively wider area and it comprises the central part of the municipality. It reaches the altitudes of $600-800$ meters a.s.l. The total of the active temperatures exceeding $10^{\circ} \mathrm{C}$ is more than $3000^{\circ} \mathrm{C}$, the number of the atmospheric precipitations during the warm period reaches $450-500 \mathrm{~mm}$.

The zone is characterized with temperately warm climate. The first freezes in the zone are observed from 25.X-27.X, and the last freezes from 9.IV-14.IV. The period without freezes continues from 191-201 days. Absolute maximum of the air temperature comprises $+39^{\circ} \mathrm{C}$ (Shiraki), absolute minimum comprises $-32^{\circ} \mathrm{C}$ (Shiraki). The zone is characterized with almost equal rapidity of north-east; east and south-east winds dominated here. From the types of soils we meet brown carbonate soils here.

In the given zone it is possible to grow corn, vegetable, fruit trees and other crops adapted to the cool conditions.

The fourth agro-climatic zone has relatively small area of distribution. It is situated on the altitude of 800-1000 $\mathrm{m}$ a.s.1. and is mainly distributed to the north-west part of the municipality. The total of the active temperatures is $3000^{\circ} \mathrm{C}$ and little less. Absolute maximum of the air temperature comprises $+38^{\circ} \mathrm{C}$ and absolute minimum comprises $-26^{\circ} \mathrm{C}$.
Annual number of atmospheric precipitations in the warm periods (IV-X) comprises $500-550 \mathrm{~mm}$.

The zone is characterized with temperate cold climate. The first freezes in the zone are observed from 21.X-24.X, and the last freezes from 15.IV-20.IV. The period without freezes continues from 183-192 days. It is possible to grow corn (early corn), potatoes, early vine, fruit trees, vegetable and other cultures here.

\subsection{Forest Resources}

Forested areas of the municipality is rather limited - 3,360 hectares, which comprises $1.3 \%$ of the whole municipality. . The forests mostly occupy the ultimate north part of the municipality and the north slopes of the Shiraki Valley, which are gradually transformed into a depression to the Alazanni Valley, also certain parts of the Vashlovani strict nature reserve. The floodplain forests are preserved on small areas, mainly on the banks of the Iori and Alazani Rivers [5].

The forests in Dedoplistskaro municipality, which is poor in forestry resources, have a multi-functional role in preserving the ecological balance. On the open-wide areas the forest protects the soil from the wind erosion and on the river gorges the forests serve as protective embankments. The role of the forest in preserving biological diversity is immense, as it represents the habitat for various species of animals and birds. The manmade windshiled lines serve with a function of migration corridor for the rare species of fauna [6].

It is worth mentioning, that stock-taking of forest in the Dedoplistskaro municiality has not taken place since 1991. Nor the inventory researches of spreading different infections within the forest regions have been conducted since 1986-2005. This is why it is very difficult more or less to evaluate the species and their condition. Though it has been defined, that among the main species in the forest (oak, hornbeam and Ash tree) rare species of trees which are on the verge of deterioration and also endemic species of trees, which are included in the list of Natural Resource Protection of the International organizations, are met. The species characterized to the arid climate (Pistachio tree and Jupiter, black and white Asp) are spread in the Vashlovani strict natural reserve and in its vicinities and the species adapted to the humid, sub-tropical climate, among them the species characterized for the tugai type forests are met in the Alazani floodplain forests [7].

\subsection{Degree of Anthropogenic Changes of Landscapes}

There are several types of landscapes in the region $[8,9,10]$ :

1. Transitional to moderate-thermophitic semi-humid forest and "shibliak" (sub-type):

- Foothill erozional-denudational landscapes with "shibliak" and hornbearn-oak (carpinus orientalis), open wood forest and Botriochloa steppes and "frigana".

The relief is erosive-accumulation and denudation-accumulation type. It is characterized with sloped foothill and plateau surface, with hillocks and depressions in some places. The surface washing is limited. The slopes with average inclination are dominated here. They are built of 
Mollass strata. The climate is sub-tropical, semi-humid, gradually transforming to moderate warm continental air. Annual number of atmospheric precipitations reaches 430-560 $\mathrm{mm}$ in average, with an expressed maximum in spring. In the rest of the periods of year the fall of precipitations are evenly distributed, though with expressed minimum in winter.

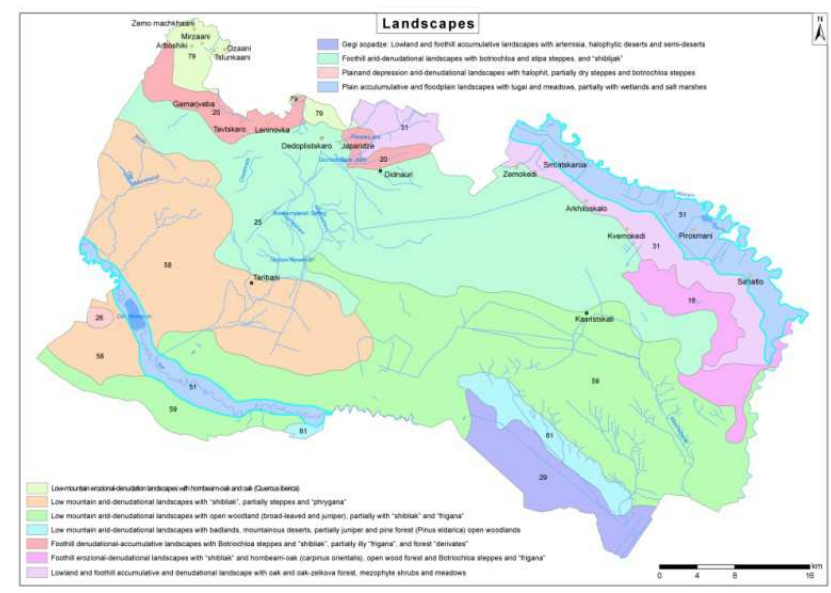

Figure 3. Landscape map of Dedoplistskaro Municipality

The relief is erosive-accumulation and denudation-accumulation type. It is characterized with sloped foothill and plateau surface, with hillocks and depressions in some places. The surface washing is limited. The slopes with average inclination are dominated here. They are built of Mollass strata.

- Foothill arid-denudational landscapes with botriochloa and stipa steppes, and "shiblijak".

2. Desert and Semidesert (sub-type):

- Lowland and foothill accumulative landscapes with artemisia, halophytic deserts and semi-deserts.

3. Transitional to Subtropical, forest:

- Lowland and foothill accumulative and denudational landscape with oak and oak-zelkova forest, mezophyte shrubs and meadows.

4. Mountainous Subtropical Arid:

- Low mountain arid-denudational landscapes with badlands, mountainous deserts, partially juniper and pine forest (Pinus eldarica) open woodlands.

\section{Recommendations}

Following recommendations were made for decision-making:

- Cleaning and restoring drainage network, which will increase water conductivity and its supply to the designated places;

- Using water resources of the Alazani River for the purposes of supplying Dedoplistskaro municipality with irrigation water, especially in its north-east part. Non-engineering and semi-engineering irrigation systems should be arranged for the irrigation of agricultural plants and the water taking should be carried out from the Alazani River.
- Iori irrigation water supply should be restored after repairing the Dali Mountain water-reservoir, because the existed water capacity especially from the tailrace does not give us a possibility to take water, the mentioned discharge is necessary for maintaining sanitary stability of the channel.

- Conductivity of the Alazani water main in Dedoplitskaro municipality comprises $3.75 \mathrm{~m} 3 / \mathrm{sec}$ and for Zilicha $1-6$ $\mathrm{m} 3 / \mathrm{sec}$. Water taking for Zilicha 1 is carried out from the Alazani River and in case of the rehabilitation of the existed channel it is possible to use it for irrigation purposes, as the river flow gives favorable conditions for that.

- In the existed conditions, development of such agricultural species should be prioritized, which do not require much water; also for the purposes of development of bee-breeding, such herbs should be planted, the flowers of which will ensure the best and optimal conditions for bees work.

- Changes of the number of sheep should be always under a strict control, because nowadays the number of sheep seems to exceed its norm, which causes overgrazing and degradation of the landscape.

- All farms should be supplied with water for avoiding movement of sheep in search of potable water, which might increase erosion of the pastures.

- Revival of wind belt lines and arranging the forest-shrubs, which, on the one hand, will reduce erosion processes and on the other hand it will contribute to the "ability" of water regulation, which has been carried out by certain landscapes in the past.

- The new technologies in the land procession should be worked out, for example instead of land plowing in the hard soil the method of cutting down should be implemented, which will gradually evade us from soil drying and wind erosions and will improve humus layer formation on the soil and consequently this will contribute to the fertilization of seeds.

- Terracing and arranging forests and shrubs on the plough plots;

- The new technologies of the irrigation systems should be worked out and implemented, for example the systems of droplet irrigation, which has been long used in the arid zones of the foreign countries.

- The alternative energy sources should be maximally used, especially bio-gas energy on the areas where the cattle farms are located; The sun energy can be used by almost every inhabitant including the wind energy, which requires a detailed study.

- Creation of "forest islands" within the pastures and forestation by means of seeding local tree plants, from this point-of-view pistachio tree is worth mentioning, which has a wide crown and strong roots. Planting these trees should be in the interests of local farmers, because at noon, when the sun is on its zenith, the cattle will lavish itself under the shadows of these trees. The Eldari pine, juniper, ash-tree and others are also worth 
mentioning.

- The population should apply energy-efficient heating system and the wood plantation for these purposes should be arranged in order to reduce illegal wood cuts in the ecological systems and to save forest resources including reduction of emissions.

- It is also necessary to contribute to the development of existed hunting activity and to enhance issuing new territories for these purposes. Other functions should be also added to the hunting activity, such as breeding the local species for the purposes of browsing the animals.

- Carrying out environment rehabilitation measures on the places of oil and ore mining.

\section{References}

[1] The first national communication of Georgia on United Nations Frame Convention of Climate Changes, Tbilisi, 1999.

[2] Impact of climate changes on Dedoplistskaro region. The second national communication preparation group of Georgia, Tbilisi. 2008
[3] L. Maruashvili. Geography of Georgia. Tbilisi, 1964. In Georgian.

[4] National Statistics of Georgia.. http://www.geostat.ge/index.php?action=0\&lang=eng

[5] A. Kodiashvili. "The process of desertification in Dedoplistskaro and its mitigation measures". Dedoplistskaro department of the protected territories. Dedoplistskaro, 2007.

[6] Nikolaishvili D., Tskhvaradze M. Influence of Climate Change on the Bioproductivity of Georgia's Landscapes. II International Scientific-Practical Conference: Bioeconomy and Sustainable Development of Agriculture. 2013. In Georgian.

[7] R. Gagnidze. "Vegetation of Georgia". Tbilisi: TSU, 2001. (In Georgian).

[8] N.L. Beruchashvili. Landscape Map of Caucasus. Tbilisi, 1979. scale 1:1,000,000. In Russian.

[9] N.L. Beruchashvili. "Caucasus: Landscapes, Models, Experiments”. Tbilisi, UNEP-GRID, 1995. In Russian.

[10] D.A. Nikolaishvili Spatial-temporal analyze of Landscapes of Georgia. Tbilisi, 2009. In Georgian. 